\title{
Emery-Dreifuss muscular dystrophy: linkage to markers in distal $\mathrm{Xq} 28$
}

\author{
J R W Yates, J P Warner, J A Smith, F Deymeer, J-P Azulay, \\ I Hausmanowa-Petrusewicz, J Zaremba, J Borkowska, N A Affara, \\ M A Ferguson-Smith
}

Department of Pathology, University of Cambridge, Cambridge.

J $R$ W Yates

J P Warner

J A Smith

N A Affara

M A Ferguson-Smith

Department of Neurology, University of Istanbul School of Medicine, Turkey. F Deymeer

Centre Hospitalier Régional et

Universitaire de Marseille, France. J-P Azulay

Department of Neurology, Medical Academy, Warsaw, Poland.

I Hausmanowa-Petrusewicz

J Borkowska

Department of Genetics, Psychoneurological Institute, Warsaw, Poland.

J Zaremba

Correspondence to Correspondence to Dr Yates, Departm Addenbrooke's Hospital, Cambridge CB2 2QQ

Received 1 August 1992 Revised version accepted 2 September 1992.

\begin{abstract}
Emery-Dreifuss muscular dystrophy (EMD) is characterised by (1) early contractures of the Achilles tendons, elbows, and postcervical muscles, (2) slowly progressive muscle wasting and weakness with a predominantly humeroperoneal distribution in the early stages, and (3) cardiomyopathy with conduction defects and risk of sudden death. Inheritance is usually $X$ linked recessive but can be autosomal dominant. Family linkage studies have mapped $X$ linked EMD to the distal long arm of the $X$ chromosome but precise genetic localisation has been hampered by the rarity of this condition. We report three new families with $X$ linked Emery-Dreifuss muscular dystrophy studied with DNA markers from Xq27-qter and three previously published families typed for additional markers. No recombination was observed with the red/green cone pigment locus, $R G C P$ (lod score, $Z=2 \cdot 46)$, the factor VIII coagulant gene locus, $F 8 C$ $(Z=6 \cdot 39)$, or with DXS115 $(Z=4 \cdot 94)$. Two recombinants were observed which mapped EMD distal to DXS15 (DX13) and DXS52 (St14) respectively. Multipoint linkage analysis gave odds exceeding 200:1 for $E M D$ being distal to these markers. A multipoint analysis incorporating published data gave the map cen-DXS304-9cM-DXS15-3cM-DXS52-2 cM-(RGCP,EMD)-3cM-F8C-2cM-DXS115 with odds of 120:1 in favour of a location for $E M D$ between $D X S 52$ and $F 8 C$ as compared to the next best position distal to $F 8 C$.

(f Med Genet 1993;30:108-11)
\end{abstract}

Emery-Dreifuss muscular dystrophy (EMD) is characterised by (1) early contractures of the Achilles tendons, elbows, and postcervical muscles, (2) slowly progressive muscle wasting and weakness with a predominantly humeroperoneal distribution in the early stages, and (3) cardiomyopathy with conduction defects. Cardiac involvement carries a substantial risk of sudden death preventable by the insertion of a pacemaker. The clinical features have been described in detail by Emery ${ }^{1}$ in a recent review. Inheritance is usually $\mathrm{X}$ linked recessive (McKusick catalogue no $310300^{2}$ ) but can be autosomal dominant (McKusick catalogue no $181350^{2}$ ). Family linkage studies have mapped $\mathrm{X}$ linked EMD to the distal long arm of the X chromosome..$^{3-11}$ Precise genetic localisation has been hampered by the rarity of the condition. Published linkage data are only available for 13 EMD families showing unequivocal $\mathrm{X}$ linked inheritance ${ }^{12}$ and only a minority of these have been comprehensively typed for Xq28 markers. We report here three new families with $\mathrm{X}$ linked Emery-Dreifuss muscular dystrophy studied with DNA markers from Xq27-qter and three previously published families typed for additional markers.

\section{Patients}

Three new families with $\mathrm{X}$ linked EmeryDreifuss muscular dystrophy were studied. The family pedigrees are shown in the figure.

\section{FAMILY 1}

Family 1 (EMD Consortium family $17^{12}$ ) is from Scotland. All subjects contributing to the linkage study were examined in their homes by JRWY and the results of previous investigations were reviewed. The diagnosis of EMD was based on the findings in III 1 who presented at 4 years of age with toe walking and distal lower limb weakness. By the age of 11 years he had contractures at the elbows with some humeral weakness and limitation of spinal flexion. The weakness progressed slowly over the next 20 years becoming predominantly proximal in the lower limbs while remaining mainly humeral in the upper limbs. Complete heart block was diagnosed at 36 years of age and treated by insertion of a cardiac pacemaker. At 43 years of age he was just able to walk with support. IV 4 showed a similar course with early contractures affecting the Achilles tendons and elbows and limitation of neck flexion apparent on examination at 18 years of age. He had atrial tachycardia with varying atrioventricular heart block. IV.11 had an abnormal gait from 3 years of age. At 6 years of age he was recorded as having a scapuloperoneal pattern of weakness with ankle dorsiflexion being particularly weak. He required lengthening of his Achilles tendons at the age of 9 years. IV 8 was examined at 8 years of age and was found to have mild weakness of hip flexion and extension, knee flexion, and ankle dorsiflexion. In all four of the affected subjects the muscle involvement was bilateral and approximately symmetrical. None showed calf hypertrophy. Intellect was normal. Serum creatine kinase varied from normal to moderately raised, the highest level 

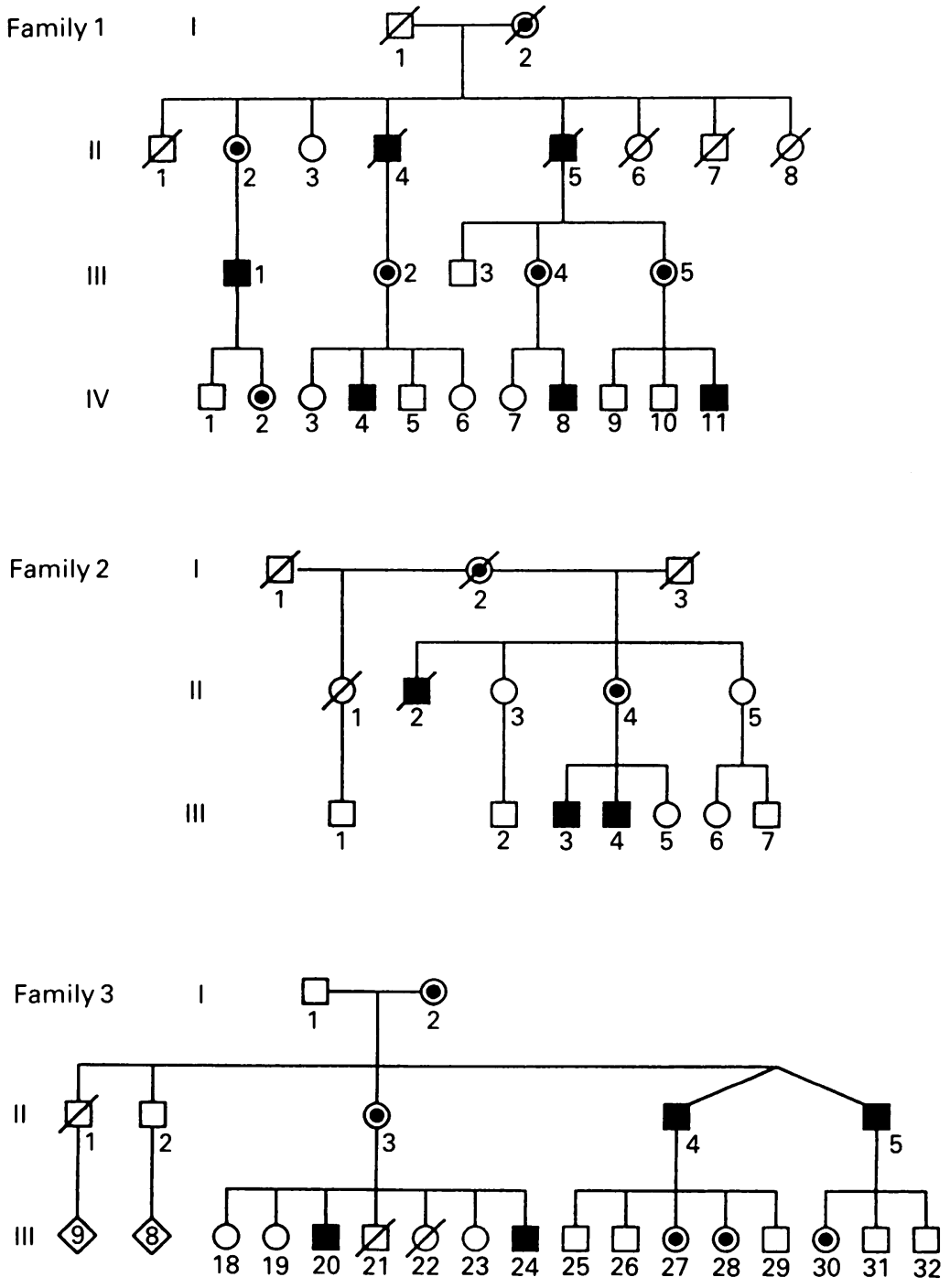

Pedigrees of EMD families 1, 2, and 3. Affected males are shaded and obligate carrier females are indicated by a central dot.

being four times the upper limit of normal. An electromyogram (EMG) in III-1 was myopathic. Muscle biopsies in III.1 and IV 11 supported a diagnosis of muscular dystrophy. None of the females in the family had evidence of muscle weakness. The unaffected male subjects IV·5, IV·9, and IV·10 were all asymptomatic at ages 20,21 , and 22 years respectively with normal cardiovascular and neurological examinations. Their serum creatine kinase measurements were normal except for IV.9 who had a level three times the upper limit of normal on first testing, but a normal level when repeated a few weeks later. None of the family was colour blind.

FAMILY 2

Family 2 from England was evaluated by JRWY. The index case, III.3, had difficulty climbing stairs from 3 years of age and was unable to straighten his arms from early childhood. He had lengthening of his Achilles tendons at 9 years of age. First degree heart block with right bundle branch block was diagnosed at 27 years of age. Heart rate varied from 35 to 87 beats per minute with pauses of up to 1.9 seconds. A cardiac pacemaker was inserted. Examination at the age of 31 years showed a waddling gait with lumbar lordosis. There were contractures of the elbows, ankles, and postcervical muscles. There was wasting and weakness most marked in the humeral, pelvic, and peroneal muscles. Tendon reflexes were absent. Spinal flexion and extension were weak. There was no calf hypertrophy. Intellect was normal. Serum creatine kinase was four times the upper limit of normal. EMG was myopathic. Muscle biopsy showed myopathic changes. III 4 suffered a similar but milder pattern of disease. Cardiological assessment at 21 years of age showed first degree heart block and partial right bundle branch block. A cardiac pacemaker was inserted. Examination at the age of 25 years showed a waddling gait with marked lumbar lordosis. There were contractures of the elbows and postcervical muscles. There was weakness of the humeral muscles. In the lower limbs there was marked peroneal weakness and lesser involvement of proximal muscles. Tendon reflexes were absent. Spinal flexion and extension were weak. There was no calf hypertrophy. Intellect was normal. Serum creatine kinase was five times the upper limit of normal. Muscle biopsy showed myopathic changes. II·2 walked on his toes from early childhood with an abnormal gait said to resemble that of the index case. In adult life he complained of episodes of chest pain and at 28 years of age he unexpectedly collapsed dead. If he was indeed affected by EMD then the pedigree shows $\mathrm{X}$ linked inheritance.

\section{FAMILY 3}

Family 3 from Turkey was evaluated by FD. The diagnosis of EMD was based on the findings in the three affected males II $\cdot 4$, II 5 , and III.20 of (1) childhood onset of slowly progressive muscle wasting and weakness with a scapulohumeroperoneal distribution, (2) early contractures of the Achilles tendons, elbows, and neck muscles, and (3) cardiac conduction defects (necessitating cardiac pacemaker insertion in II.4 and II·5). Serum creatine kinase levels were normal or mildly raised. A muscle biopsy in II. 5 showed dystrophic changes. The pedigree shows unequivocal $\mathrm{X}$ linked inheritance. Full details of this family will be published elsewhere.

\section{Methods}

Blood samples were obtained from available family members, DNA extracted by routine methods, and DNA polymorphisms analysed by Southern analysis or the polymerase chain reaction using standard protocols. The families were typed for the DNA markers DXS304 (probe U6.2/TaqI restriction digest), DXS52 (St14-1/TaqI), DXS15 (DX13/BglII), RGCP (HS7/SacI), F8C (p114.12/BclI), and DXS115 (767/Bst XI) as detailed elsewhere. ${ }^{13}$

Additional linkage data were obtained by completing the typing of the above markers in two families we have reported previously ${ }^{5}$ (EMD Consortium families 5 and $6^{12}$ ) and in a 
third family reported by Paquis et al ${ }^{9}$ (EMD Consortium family $9^{12}$ ).

All six families studied meet the diagnostic criteria drawn up by the EMD Consortium for families being used in linkage studies in $\mathrm{X}$ linked EMD. ${ }^{12}$ The clinical features in four of the families (EMD Consortium families 5, 6, 9, and 17) were reviewed at the European Workshop on EMD (1991) and accepted as meeting these criteria. ${ }^{12}$

Linkage data were analysed using the computer programmes LIPED ${ }^{14}$ and LINKMAP ${ }^{15}$ for two point and multipoint analyses respectively. Confidence intervals were obtained by taking values of the recombination fraction corresponding to a lod score one unit less than the maximum. ${ }^{16}$ Published multiple pairwise data were analysed with the computer programme $\mathrm{MAP}^{17}$ using the Rao mapping function $^{18}$ with an interference parameter value of 0.35 .

\section{Results}

Two point lod scores between EMD and marker loci are given in the table. No recombinants were observed with $R G C P$ (HS7), F8C, or $D X S 115$ (767). EMD Consortium family 5 showed a recombinant between EMD and DXS52 (St14-1) as we have previously reported $^{5}$ with two affected brothers having different restriction fragment patterns at this locus. They had the same marker patterns for DXS15 (DX13) and F8C but their obligate carrier mother was dead and could have been homozygous at these loci. In the present study these results were confirmed on repeat blood samples and additional typing showed that they were also recombinant for the more proximal marker DXS304 (U6.2) but had the same marker patterns for $R G C P$ and $D X S 115$. Consortium family 9 showed a recombinant between EMD and DXS15 as previously reported $^{9}$ with two affected brothers having different restriction fragment patterns at this locus. More proximal markers were also recombinant, $D X S 52$ was uninformative, and $F 8 C$ was non-recombinant. In the present study these results were confirmed on repeat blood samples and additional typing showed that $R G C P$ was non-recombinant.

For the multipoint analysis we used the marker order DXS304 (proximal), DXS15, $D X S 52, R G C P, F 8 C, D X S 115$ (distal) with recombination fractions of $0.09,0.03,0.02$, $0.03,0.02$, respectively, calculated by multiple pairwise analysis of published linkage data. ${ }^{19}$ This order is consistent with recent physical mapping data ${ }^{20}$ except that the order of
DXS15 and DXS52 is not well established. The pairwise analysis provided weak support for $D X S 15$ being the more proximal marker.

In the LINKMAP analysis the maximum location score was 38.5 with EMD coincident with $F 8 C$. This position was favoured by odds of 200:1 compared to a location between DXS52 and DXS15 and by odds exceeding 1000:1 compared to all locations proximal to these markers. If the order of DXS15 and DXS52 were reversed, the maximum location score was 38.8 with $E M D$ coincident with $F 8 C$ and this position was supported by odds exceeding 1000:1 compared to all locations proximal to $D X S 15$. In the absence of recombinants it was not possible to determine order with respect to $R G C P, F 8 C$, or $D X S 115$.

A second LINKMAP analysis incorporated published data for which haplotype information is available, taken from Thomas et al $1972,{ }^{3}$ family A of Romeo et al 1988, ${ }^{7}$ and Cole et al $1992^{21}$ (EMD Consortium families 1, 2, 3, and $8^{12}$ ). The maximum location score was 66.1 with $E M D$ coincident with $R G C P$. This position was supported by odds of $120: 1 \mathrm{com}$ pared to the next highest location score when $E M D$ was coincident with $D X S 115$. The odds against locations proximal to $D X S 52 / D X S 15$ exceeded 10 000:1.

\section{Discussion}

The results presented here map the EmeryDreifuss muscular dystrophy locus (EMD) close to the factor VIII coagulant gene locus $(F 8 C)$ in $\mathrm{Xq} 28$ and are consistent with previously reported data. Until recently there was uncertainty about the order of markers in the vicinity of $F 8 C$ but from the physical mapping data of Poustka et $a l^{20}$ it now seems that the most likely order is cen-DXS304-DXS52, DXS15-RGCP-F8C-DXS115-qter. Provided this order is correct, the recombinants reported previously ${ }^{59}$ and now confirmed and further characterised in this report map $E M D$ distal to DXS15 (DX13) and DXS52 (St14). This is consistent with the recombinant with DXS52 and DXS15 identified by Hodgson et $a l^{4}$ and confirmed in a subsequent report. ${ }^{21}$ Taken together these data provide strong evidence for a distal location for the Emery-Dreifuss muscular dystrophy locus within a region estimated at $3 \mathrm{Mb}$ from DX13 to the telomere. $^{20}$

A recombinant recently reported by Cole $e t$ $a l^{21}$ maps $E M D$ proximal to $F 8 C$. This finding has been fully validated by clinical review of key family members, repeat blood sampling, and independent confirmation of the marker

Two point lod scores between Emery-Dreifuss muscular dystrophy and the DNA markers DXS304 (U6.2), DXS15 (DX13), DXS52 (St14), RGCP, F8C, and DXS115 (767).

\begin{tabular}{|c|c|c|c|c|c|c|c|c|c|c|}
\hline \multirow[t]{2}{*}{ Locus } & \multicolumn{7}{|c|}{ Lod score $\mathrm{Z}$ at recombination fraction $\theta$} & \multirow[t]{2}{*}{ Zmax } & \multirow[t]{2}{*}{$\theta \max$} & \multirow{2}{*}{$\begin{array}{l}\text { Confidence } \\
\text { interval for } \theta\end{array}$} \\
\hline & 0 & 0.001 & 0.05 & $0 \cdot 1$ & $0 \cdot 2$ & $0 \cdot 3$ & 0.4 & & & \\
\hline $\begin{array}{l}D X S 304 \\
D X S 15 \\
D X S 52 \\
R G C P \\
F 8 C \\
D X S 115\end{array}$ & $\begin{array}{l}-\infty \\
-\infty \\
-\infty \\
2 \cdot 46 \\
6 \cdot 39 \\
4.94\end{array}$ & $\begin{array}{l}1.11 \\
1 \cdot 79 \\
4.06 \\
2.46 \\
6.38 \\
4.93\end{array}$ & $\begin{array}{l}2 \cdot 50 \\
3 \cdot 13 \\
5 \cdot 22 \\
2 \cdot 26 \\
5 \cdot 85 \\
4 \cdot 49\end{array}$ & $\begin{array}{l}2 \cdot 47 \\
3 \cdot 04 \\
4 \cdot 95 \\
2 \cdot 04 \\
5 \cdot 29 \\
4 \cdot 02\end{array}$ & $\begin{array}{l}2 \cdot 07 \\
2 \cdot 52 \\
4.02 \\
1.58 \\
4 \cdot 12 \\
3.04\end{array}$ & $\begin{array}{l}1.50 \\
1.81 \\
2.86 \\
1.08 \\
2.86 \\
1.99\end{array}$ & $\begin{array}{l}0.81 \\
0.97 \\
1.52 \\
0.54 \\
1.50 \\
0.90\end{array}$ & $\begin{array}{l}2 \cdot 51 \\
3 \cdot 13 \\
5 \cdot 23 \\
2 \cdot 46 \\
6 \cdot 39 \\
4 \cdot 94\end{array}$ & $\begin{array}{l}0.07 \\
0.06 \\
0.04 \\
0.0 \\
0.0 \\
0.0\end{array}$ & $\begin{array}{c}0.003-0 \cdot 30 \\
0 \cdot 002-0 \cdot 26 \\
0.002-0 \cdot 18 \\
0-0 \cdot 23 \\
0-0.09 \\
0-0 \cdot 11\end{array}$ \\
\hline
\end{tabular}


typing by a second laboratory. Conflicting data from another family apparently mapping $E M D$ distal to $F 8 C^{22}$ has recently been withdrawn after review of the clinical status of the relevant family members. ${ }^{23}$

All the current data are therefore consistent in placing $E M D$ between $D X S 15 / D X S 52$ and $F 8 C$. This location is supported by odds of 120:1 in the LINKMAP analysis presented here incorporating published data for which haplotype information is available. This corresponds to a physical distance of approximately $2 \mathrm{Mb} .{ }^{20}$ Further family studies will be needed to confirm $F 8 C$ as a distal flanking marker. Better localisation will also be dependent on having new markers from this interval so that flanking recombinants can be mapped precisely.

We are most grateful to the families who have cooperated with this study and to the many colleagues who have provided clinical information and helped with the collection of samples, particularly Dr Barbara Badurska, Dr Clare Davison, Dr Graham Cook, Professor Alan Emery, Mrs Marie Ferguson-Smith, Dr Anna Fidzianska, Dr David Gardner-Medwin, Professor Jean Pouget, and Dr Barbara Ryniewicz. For technical help we thank Doreen Jamieson, Susan Newby, and Dr Rob McMahon. The support of the Muscular Dystrophy Group of Great Britain is gratefully acknowledged.

1 Emery AEH. Emery-Dreifuss syndrome. 7 Med Genet 1989;26:637-41.

2 McKusick VA. Mendelian inheritance in man. Baltimore: McKusick VA. Mendelian inheritance in
Johns Hopkins University Press, 1990.

3 Thomas PK, Calne DB, Elliott CF. X-linked scapuloperoneal syndrome. $f$ Neurol Neurosurg Psychiatry 1972;35:208-15.

4 Hodgson S, Boswinkel E, Cole C, et al. A linkage study of Emery-Dreifuss muscular dystrophy. Hum Genet 1986;74:409-16.

5 Yates JRW, Affara NA, Jamieson DM, et al. Emery-

Dreifuss muscular dystrophy: localisation to
Xq27.3 $\rightarrow$ qter confirmed by linkage to the factor VIII gene. 7 Med Genet 1986;23:587-90.

6 Thomas NST, Williams H, Elsas LJ, Hopkins LC, Sarfarazi M, Harper PS. Localisation of the gene for Emeryazi M, Harper PS. Localisation of the gene for EmeryDreifuss muscular dystrophy to the distal long arm of the
$\mathrm{X}$ chromosome. 7 Med Genet $1986 ; 23: 596-8$.

X chromosome. I Med Genet 1986;23:596-8.
Romeo G, Roncuzzi L, Sangiorgi S, et al. Mapping of the Romeo G, Roncuzzi L, Sangiorgi S, et al. Mapping of the
Emery-Dreifuss gene through reconstruction of crossover points in two Italian pedigrees. Hum Genet 1988;80:5962 .

8 Goldblatt J, Schram LJ, Wallis G, Oswald A, Beighton P. Emery-Dreifuss syndrome and $\mathrm{X}$-linked muscular dystrophy with contractures: evidence for homogeneity. Clin Genet 1989;35:1-4.

9 Paquis V, Philip N, Voelckel MA, et al. Études de liaison dans la dystrophie musculaire d'Emery-Dreifuss. $f$ Genet Hum 1989;37:127-32.

10 Consalez GG, Thomas NST, Stayton CL, et al. Assignment of Emery-Dreifuss muscular dystrophy to the distal region of Xq28: the results of a collaborative study. $A \mathrm{~m}^{\prime}$ Hum Genet 1991;48:468-80.

11 Wehnert M, Machill G, Grimm T, et al. Evidence supporting linkage of Emery-Dreifuss muscular dystrophy to the ing linkage of Emery-Dreifuss muscular dystrophy to the 1991;58:2089.

12 Yates JRW. European workshop on Emery-Dreifuss musYates JRW. European workshop on Emery-Dreifuss
cular dystrophy 1991. Neuromusc Dis 1991;1:393-6.

13 Williamson R, Bowcock A, Kidd K, et al. Report of the DNA committee and catalogues of cloned and mapped genes, markers formatted for PCR and DNA polymorphisms. HGM11. Cytogenet Cell Genet 1991;58:1190832.

14 Ott J. Estimation of the recombination fraction in human pedigrees. Efficient computation of the likelihood for human linkage studies. Am f Hum Genet 1974;26:588-97.

15 Lathrop GM, Lalouel JM, Julier C, Ott J. Strategies for 政 USA 1984;81:3443-6.

16 Conneally PM, Edwards JH, Kidd KK, et al. Report of the committee on methods of linkage analysis and reporting. committee on methods of linkage analysis and

17 Morton NE, Andrews V. MAP, an expert system for multiple pairwise linkage analysis. Ann Hum Genet 1989;53:263-9.

18 Rao DC, Morton NE, Lindsten J, Hulten M, Yee S. A mapping function for man. Hum Hered 1977;27:99-104.

19 Keats B, Ott J, Conneally M. Report of the committee on linkage and gene order. HGM10. Cytogenet Cell Genet 1989;51:459-502.

20 Poustka A, Dietrich A, Langenstein G, Toniolo D, Warren ST, Lehrach H. Physical map of human Xq27-qter: localizing the region of the fragile $\mathrm{X}$ mutation. Proc Nat Acad Sci USA 1991;88:8302-6.

21 Cole CG, Abbs SJ, Dubowitz V, et al. Linkage of EmeryDreifuss muscular dystrophy to the red/green cone pigment (RGCP) genes, proximal to factor VIII. Neuromusc ment (RGCP) gent

22 Kullmann F, Kausch K, Kress W, et al. Evidence for location of Emery-Dreifuss muscular dystrophy on distal Xq28. In: Vogel W, Just W, eds. Abstracts, German
Society of Human Genetics. Ulm: Universitätsverlag Ulm GmbH, 1991:229.

23 Kress W, Müller E, Kausch K, et al. Multipoint linkage mapping of the Emery-Dreifuss muscular dystrophy gene. Neuromusc Dis 1992;2:111-5. 